\title{
Development of Non-Point Source Hybrid Cells in Series Model for Reactive Pollutant Transport in Natural Rivers
}

\author{
Joy Tuoyo Adu, Muthukrishna Vellaisamy Kumarasamy* \\ Civil Engineering Programme, School of Engineering, University of KwaZulu-Natal, Durban, South Africa
}

Received: 1 February 2019

Accepted: 28 April 2019

\begin{abstract}
Studies in recent years have shown that most reactive pollutants in natural rivers originate from non-point sources such as agricultural lands and informal settlements through rainfall runoff. Much work has centred on simulating decaying substances in rivers from point-source discharges. To expand on the area of non-point source modelling in rivers, a non-point source hybrid cells in series model for simulation of reactive pollutants in rivers is proposed. The potential of the proposed model has been demonstrated and found to simulate decay from non-point sources in streams and rivers satisfactorily. The proposed model is compared with the numerical solution of the ADE model with added components for non-point source and first-order reaction kinetic. The comparisons indicate reasonably good agreement. The breakthrough curves obtained from the proposed model shows its capability to simulate reactive pollutant transport in natural rivers effectively.
\end{abstract}

Keywords: reactive pollutants, decay, hybrid cells in series model, non-point source

\section{Introduction}

Pollutants from point and or non-point sources when released into water bodies follow a scheme of occurrences $[1,2]$. Generally, the presence of pollutants classified as either conservative or non-conservative/ reactive makes rivers unfit for any kind of use. Rivers naturally have a self-purifying mechanism which restores its balance. However, when pollutant loads exceed the self-cleansing capacity of the river, the entire eco-system becomes distorted [3, 4]. Reactive pollutants which are subject to decay constitute most freshwater

*e-mail: kumarasamy@ukzn.ac.za pollutants [5-8]. A large proportion of reactive pollutants are identified as being sourced from nonpoint sources through runoff mainly from agricultural lands and informal settlements [3, 5, 8-10]. The pollutant contributions from non-point sources influence in-stream water quality of usable water considerably with its impact felt downstream in the river network [11-13]. The processes that occur within the water body over time decide the fate of the pollutants as they undergo chemical and or biological changes within the water channel due to decay. These processes influence the pollutant concentration as it moves downstream from the source of entry. Depletion of oxygen, excessive toxic algae growth from the enrichment of the water body due to excess nutrient loading and loss of biodiversity in the eco-system are direct results of 
these occurrences. Quantifying these processes and their effects, therefore, has become necessary. This is of even more importance when such pollutants are generated from non-point sources [14, 15]. In this regard, water quality management requires indepth understanding of the distribution and behaviour of pollutants within the river in order to restore its quality to acceptable levels. The difficulties associated with the behaviour of reactive contaminants in waterways informs the need for simplified interpretive models. It is essential that the model does not require extensive data input for calibration, and that the necessary data can be obtained with reasonable resource allocation.

Extensive research relating to modelling of transport of reactive substances that focus on predictions of instream pollutant concentration, the fate of in-stream fluxes and the threat of nutrient pollution in rivers generated from point sources have been carried out [16]. However, not much has been done in relation to contributions from non-point sources (NPS) since it is cumbersome to predict when compared to point source pollution [14]. This forms the motivation for this work: to develop an in-stream non-point source pollution model for simulation of non-conservative pollutants. This is essential considering, as earlier mentioned, that significant amounts of nutrients and reactive pollutants generated from agricultural lands and informal settlements find their way into surface water through rainfall run-off, otherwise classified as non-point sources [9, 10, 17-19]. Consequently, the development of a simulation tool for water quality management of streams and rivers susceptible to reactive pollutant build-up from non-point sources is necessary. Such a tool is required in order to understand the movement of such pollutants along natural watercourses for effective pollution management. The ability to easily predict the water quality status of streams and rivers would ease water quality treatment, monitoring, and management processes, which by extension would curb the scarcity of usable water.

\section{Theory}

Decay is generally approximated by a first-order kinetic equation where concentration with respect to time and distance is expressed as Eq. (1) [20]:

$$
C(x, t)=\frac{x}{2 t \sqrt{\pi D_{L} t}} \exp \left[\frac{-(x-u t)^{2}}{4 D_{L} t}-k t\right]
$$

Eq. (1) is the analytical solution of the classical advection dispersion equation (ADE) model for impulse injection of reactive pollutants for steady and uniform flow conditions in rivers [14, 20]. A major challenge, however, lies in the estimation of the dispersion coefficient of the solute. Fischer [21] used the routing method to estimate dispersion coefficient by matching predicted concentration-time profiles with measured concentration-time profiles for assumed values of dispersion, until a minimal difference between both patterns as measured by the sum of squared differences is achieved. This method is cumbersome and in practice difficult to measure. Also, according to Benedini and Tsakiris [22], the ADE does not entirely represent the on-site observations of the behaviour of pollutants in natural rivers accurately. This shortcoming has led to several modelling attempts, including the hybrid cells in series (HCIS) model [23]. Since a significant proportion of pollutants from non-point sources have been identified as being subject to decay, the HCIS model will be further extended to include the NPS and decay component. Therefore, without aiming at a specific type of reactive pollutant, this study seeks to incorporate a first-order decay kinetic component to the HCISNPS model for the simulation of non-conservative contaminants in rivers.

\section{Hybrid Cells in Series (HCIS)}

The HCIS model developed by Ghosh [23] as an alternative model to the Fickian-based ADE and other associated models for solute transport in natural streams and rivers has been further developed over the years with the inclusion of other components. Kumarasamy et al. [4] developed a hybrid cell in series model to simulate pollutant transport with first-order decay kinetics in order to predict the concentration of non-conservative point source pollutants in natural rivers. In the model, Kumarasamy et al. [4] considers that the decay of pollutants in the water body is governed by the Streeter-Phelps first-order reaction kinetics Eq. (2) [24].

$$
\frac{d C(x, t)}{d t}=-k_{a} C(x, t)
$$

...where $k a$ (per min) is the first-order decay constant and $C(x, t)(\mathrm{mgl}-1)$ is the concentration of the pollutant in the water. The negative sign shows pollutant abatement or decay [24-26]. The proposed HCIS-NPSk model consists of a plug flow zone and two thoroughly mixed zones connected in series and with unequal residence time. Determination of the residence time is based on the volume $(V)$ and the flow rate $(Q)$ within each zone. As pollutants are introduced into the plug flow zone, no mixing occurs but the injected flux is replaced over time as it flows downstream and into the first mixing zone where mixing occurs. The effluent from the first mixing zone moves into the second zone, where mixing also takes place. The decay of pollutants occurs in all three zones. 


\section{Model Parametrization}

The HCIS model has three independent residence time parameters within each zone: $\alpha$ represents the residence time in the plug flow zone, $T_{1}$ is residence time in the first mixing zone and $T_{2}$ is residence time in the second mixing zone. These time parameters are determined using the longitudinal dispersion coefficient $\left(D_{L}\right)$ and mean flow velocity $(u)$ in relation with the Peclet number $(\mathrm{Pe})$. The relationship between pollutant transport mechanisms is defined by the Peclet number. Therefore, the conditions $P e=\Delta x u / D L \geq 4$ must be satisfied in order to produce an acceptable C-t profile. The size of the hybrid unit $(\Delta x)$ is determined from this relationship and is used for estimating $\alpha, T_{l}$, and $T_{2}$ as follows [23, 27, 28]. The model parameters can, however, be obtained using the least square optimization method:

$$
\begin{gathered}
\alpha=\frac{0.04 \Delta x^{2}}{D_{L}} \\
T_{1}=\frac{0.05 \Delta x^{2}}{D_{L}} \\
T_{2}=\frac{\Delta x}{u}-\frac{0.09 \Delta x^{2}}{D_{L}}
\end{gathered}
$$

\section{Formulation of the Model}

The conceptualised HCIS-NPS model, which incorporates decay processes of first-order reaction kinetics, is made up of a plug flow zone and two wellmixed zones with unequal residence times that are connected in series (Fig. 1). As the non-conservative pollutant moves through the plug zone, the moving plume is replaced in $\alpha$ time by pure advection with minimal drop in pollutant concentration due to decay. The effluent flows into the first mixing zone with residence time $T_{l}$, where thorough mixing takes place through the joint process of advection and dispersion. Decay of the pollutants occurs in this zone. Subsequently, after $T$, time, the effluent moves into the second mixing zone with residence time $T_{2}$, where continuous mixing and decay also occur.

\section{Deriving Pollutant Concentration Through the Plug Flow Zone}

The initial and boundary conditions that express the initial state of pollution and concentration at the boundary of the river are set as $C(x, 0)=0 ; x>0$, $\mathrm{C}(0, t)=C_{R} ; t \geq 0$ and $C(\alpha u, t)=0 ; 0<t<\alpha$. The initial boundary concentration of pollutants in each zone changes from zero to $C_{R}$ with time.

The plug flow zone of the HCIS-NPS $k$ model, which has a conceptualised control volume $V$ and length $\Delta x$ and is subject to advection processes, lateral inflow and first-order decay of pollutant, is expressed as shown in the following mass balance equation:

$$
\frac{\partial C(x, t)}{\partial t}=-u \frac{\partial C(x, t)}{\partial x}+\frac{q_{L}}{A}\left(C_{L}-C(x, t)\right)-k_{a} C(x, t)
$$

...where $C(x, t)$ is the pollutant concentration in the water body $\left(\mathrm{mgl}^{-1}\right), u$ is flow velocity of the water body $\left(\mathrm{ms}^{-1}\right), t$ is time interval of solute displacement (s), $x$ is distance from source $(\mathrm{m}), q_{L}$ is lateral inflow $\left(\mathrm{m}^{3} \mathrm{~s}^{-1} \mathrm{~m}^{-1}\right)$, $C_{L}$ is pollutant concentration in lateral inflow $\left(\mathrm{mgl}^{-1}\right), k_{\mathrm{a}}$ is the first-order decay constant $\left(\mathrm{s}^{-1}\right)$, and $A$ is the crosssectional area of the water channel $\left(\mathrm{m}^{2}\right)$. Henceforth, $q_{L} / A$ is denoted as $\psi$ while $\epsilon=\psi+k_{a}$. Taking the Laplace transformation of all terms in Eq. (6) reduces it to:
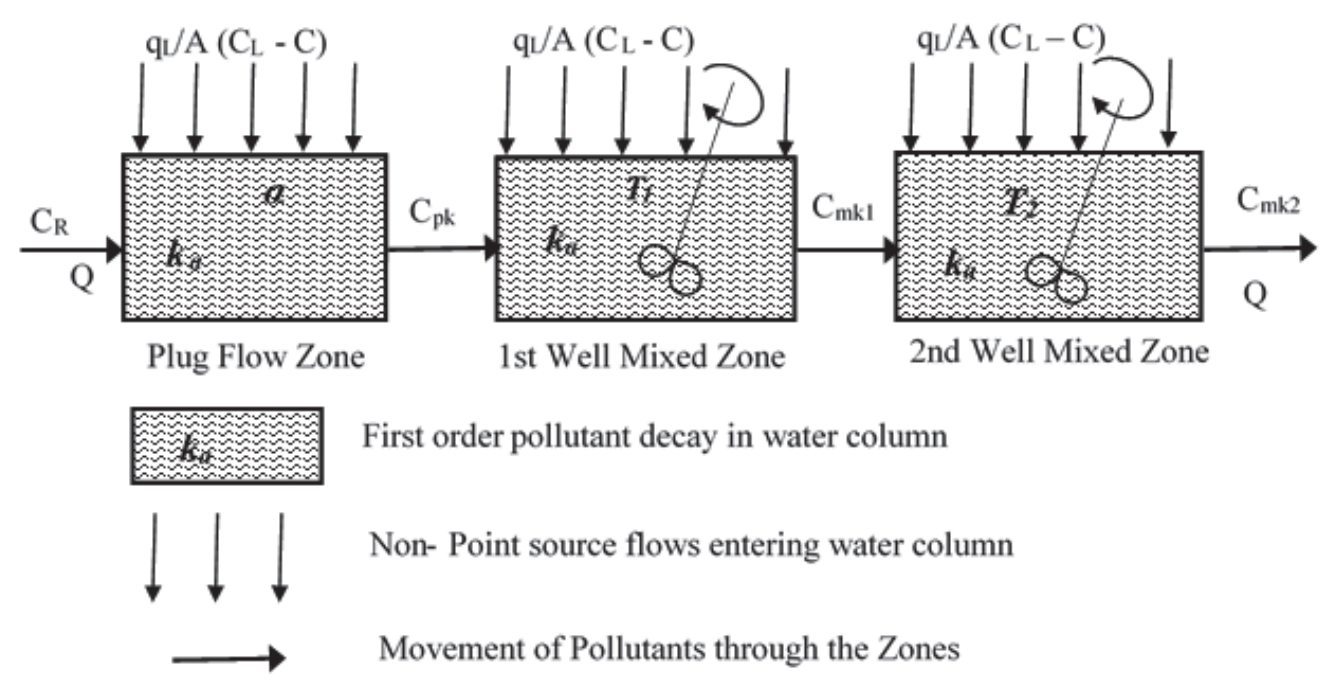

Fig. 1. HCIS-NPS unit with in-stream first-order kinetic reactions. 


$$
u \frac{d C^{*}}{d x}=-S C^{*}-\in C^{*}+\psi C_{L}
$$

Simplifying Eq. (7) yields

$\frac{d C^{*}}{d x} \exp ^{+\left[\frac{S+\epsilon}{u}\right] x}+\left[\frac{S+\epsilon}{u}\right] C^{*} \exp ^{+\left[\frac{S+\epsilon}{u}\right] x}=\frac{\psi}{u} C_{L} \exp ^{+\left[\frac{S+\epsilon}{u}\right] x}$

Eq. (8) is solved by integration, when $x=0, C=C_{R}$ $+C_{L}$ and $C^{*}=C_{R} / S+C_{L} / S$. Then, solving by taking inverse Laplace transforms yields:

$$
\begin{gathered}
C_{P k}(\alpha u, t)=C_{R} U(t-\alpha) \exp ^{-\epsilon \alpha}+C_{L} U(t-\alpha) \exp ^{-\epsilon \alpha} \\
-\psi C_{L} U(t-\alpha) \exp ^{-\epsilon t}+\psi C_{L} \exp ^{-\epsilon t}
\end{gathered}
$$

Eq. (9) represents the pollutant concentration of pollutants at the end of the plug flow zone for pollutants subject to decay when $t \geq \alpha$. While $U(t-\alpha)$ is the step function that ranges from 0 when $t<\alpha$ to 1 when $t \geq \alpha$.

\section{Deriving Pollutant Concentration Through the First well Mixed Zone}

Effluent from the plug flow zone, Eq. (9), having moved through the plug flow zone over a distance in $\alpha$ time, forms the influent to the first mixed zone. The change in solute concentration in the zone, the effluent mass leaving the plug flow zone into the first well mixed zone, the effluent moving through the first mixing zone, the uniformly distributed lateral inflow into the zone and the mass decayed within the zone are all accounted for. The mass balance for the first mixing zone is given as Eq. (10). All terms follow the sequence as listed in the presentation of the equation.

$$
\begin{aligned}
V_{1} \Delta C_{M k 1}=C_{P k} Q \Delta t & -C_{M k 1} Q \Delta t+\frac{q_{L}}{A}\left(C_{L}-C_{M k 1}\right) V_{1} \Delta t \\
& -k_{a} C_{M k 1} V_{1} \Delta t
\end{aligned}
$$

...where $V_{1}$ is the volume of the first well mixed zone and $Q$ is the flow rate of solute within the zone. The filling time within this zone is $T_{1}=V_{l} / Q$. Thus, rewritten in differentials, Eq. (10) becomes:

$$
\begin{gathered}
\frac{d C_{M k 1}}{d t}=\frac{C_{R} U(t-\alpha) \exp ^{-\epsilon \alpha}}{T_{1}}+\frac{C_{L} U(t-\alpha) \exp ^{-\epsilon \alpha}}{T_{1}} \\
-\frac{\psi C_{L} U(t-\alpha) \exp ^{-\epsilon t}}{T_{1}}+\frac{\psi C_{L} \exp ^{-\epsilon t}}{T_{1}} \\
-\left[\frac{1+\epsilon T_{1}}{T_{1}}\right] C_{M k 1}+\psi C_{L}
\end{gathered}
$$

The solution of Eq. (11) gives the pollutant concentration at the end of the first well mixed zone with decay occurring as expressed in Eq. (12), which is valid when $t \geq \alpha$ :

$$
\begin{aligned}
C_{M k 1}= & \frac{C_{R} U(t-\alpha) \exp ^{-\epsilon \alpha}}{1+\in T_{1}}+\frac{C_{L} U(t-\alpha) \exp ^{-\alpha \alpha}}{1+\in T_{1}} \\
-\psi C_{L} U(t-\alpha) \exp ^{-\epsilon t}+\psi C_{L} \exp ^{-\epsilon t}+\frac{\psi C_{L} T_{1}}{1+\in T_{1}} & \\
& -\frac{C_{R} U(t-\alpha) \exp ^{-\epsilon \alpha} \exp ^{-\left[\frac{1+\in T_{1}}{T_{1}}\right](t-\alpha)}}{1+\in T_{1}} \\
& -\frac{C_{L} U(t-\alpha) \exp ^{-\alpha \alpha} \exp ^{-\left[\frac{1+\in T_{1}}{T_{1}}\right](t-\alpha)}}{1+\in T_{1}} \\
& +\psi C_{L} U(t-\alpha) \exp ^{-\epsilon \alpha} \exp ^{-\left[\frac{1+\in T_{1}}{T_{1}}\right](t-\alpha)} \\
-\psi C_{L} & \exp ^{-\left[\frac{1+\in T_{1}}{T_{1}}\right](t-\alpha)}-\frac{\psi C_{L} T_{1} \exp ^{-\left[\frac{1+\in T_{1}}{T_{1}}\right](t-\alpha)}}{1+\in T_{1}}
\end{aligned}
$$

Deriving Pollutant Concentration Through the Second Well Mixed Zone

Similarly, outflow from the first well mixed zone, $C_{M K l}$, becomes the infeed to the second well mixed zone. With filling time of $T_{2}=V_{2} / Q$, where $V_{2}$ is the volume of the zone. Subsequently, the mass balance for the second well mixed zone is:

$$
\begin{gathered}
V_{2} \Delta C_{M k 2}=C_{M k 1} Q \Delta t-C_{M k 2} Q \Delta t \\
+\frac{q_{L}}{A}\left(C_{L}-C_{M k 2}\right) V_{2} \Delta t-k_{1} C_{M k 2} V_{2} \Delta t
\end{gathered}
$$

Divide Eq. (13) through by $V_{2} \Delta t$ and written in differentials yields:

$$
\begin{aligned}
\frac{d C_{M k 2}}{d t}= & \frac{C_{R} U(t-\alpha) \exp ^{-\epsilon \alpha}}{T_{2}\left(1+\in T_{1}\right)}+\frac{C_{L} U(t-\alpha) \exp ^{-\epsilon \alpha}}{T_{2}\left(1+\in T_{1}\right)} \\
& -\frac{\psi C_{L} U(t-\alpha) \exp ^{-\epsilon t}}{T_{2}}+\frac{\psi C_{L} \exp ^{-\epsilon t}}{T_{2}} \\
& -\frac{C_{R} U(t-\alpha) \exp ^{-\epsilon \alpha} \exp ^{-\left[\frac{1+\in T_{1}}{T_{1}}\right](t-\alpha)}}{T_{2}\left(1+\in T_{1}\right)} \\
& -\frac{C_{L} U(t-\alpha) \exp ^{-\epsilon \alpha} \exp ^{-\left[\frac{1+\in T_{1}}{T_{1}}\right](t-\alpha)}}{T_{2}\left(1+\in T_{1}\right)}
\end{aligned}
$$




$$
\begin{gathered}
+\frac{\psi C_{L} U(t-\alpha) \exp ^{-\Theta \alpha} \exp ^{-\left[\frac{1+\in T_{1}}{T_{1}}\right](t-\alpha)}}{T_{2}} \\
-\frac{\psi C_{L} \exp ^{-\epsilon \alpha} \exp ^{\left[\frac{1+\in T_{1}}{T_{1}}\right](t-\alpha)}}{T_{2}}
\end{gathered}
$$

$-\frac{\psi C_{L} T_{1} \exp ^{-\left[\frac{1+\in T_{1}}{T_{1}}\right](t-\alpha)}}{T_{2}\left(1+\in T_{1}\right)}-\left[\frac{1+\psi T_{2}}{T_{2}}\right] C_{M k 2}+\psi C_{L}-k_{a} C_{M k 2}$

Integrating Eq. (14) with respect to " $t$ " yields:

$$
\begin{gathered}
C_{M k 2}=K_{H C I S-N S S k}=\frac{C_{R} U(t-\alpha) \exp ^{-\alpha \alpha}}{\left(1+\in T_{1}\right)}\left[B_{1}\right] \\
+\frac{C_{L} U(t-\alpha) \exp ^{-\epsilon \alpha}}{\left(1+\in T_{1}\right)}\left[B_{1}\right]-\psi C_{L} U(t-\alpha)\left[B_{2}-B_{3}\right] \\
+\psi C_{L}\left[B_{2}-B_{3}\right]+\frac{\psi C_{L} T_{1}}{\left(1+\in T_{1}\right)}\left[B_{1}\right]+\frac{\psi C_{L} T_{2}}{\left(1+\in T_{2}\right)}\left[B_{4}\right]
\end{gathered}
$$

...where:

$$
\begin{aligned}
& B_{1}=\left[\frac{1-\exp ^{\left[\frac{1+\in T_{2}}{T_{2}}\right](t-\alpha)}}{\left(1+\in T_{2}\right)}-\frac{T_{1}\left[\exp ^{-\left[\frac{1+\in T_{1}}{T_{1}}\right](t-\alpha)}-\exp ^{\left[-\left[\frac{1+\in T_{2}}{T_{2}}\right](t-\alpha)\right.}\right]}{\left(T_{1}-T_{2}\right)}\right], \\
& B_{2}=\left[\exp ^{-\epsilon t}-\exp ^{-\alpha x} \exp ^{-\left[\frac{1+T_{2}}{T_{2}}\right](t-\alpha)}\right], \\
& B_{3}=\left[\frac{T_{1} \exp ^{-\epsilon \alpha}\left[\exp ^{\left[\frac{1+\in T_{1}}{T_{1}}\right](t-\alpha)}-\exp ^{-\left[\frac{1+\in T_{2}}{T_{2}}\right](t-\alpha)}\right]}{\left(T_{1}-T_{2}\right)}\right] . \\
& B_{4}=\left[1-\exp ^{-\left[\frac{1+\in T_{2}}{T_{2}}\right](t-\alpha)}\right]
\end{aligned}
$$

Eq. (15) is the effluent concentration and the step response $K_{\text {HCIS-NPSk }}$ at the end of the first hybrid unit. Valid when $t \geq \alpha$. $\alpha$ is the residence time in the plug flow zone.

The response to unit impulse perturbation $k_{\text {HCIS-NPSk }}$ at the end of the first hybrid unit is derived when $K_{\text {HCIS-NPS } k}$ is differentiated with respect to (t) as given in Eq. (16) to yield Eq. (17):

$$
\begin{gathered}
k_{H C I S-N P S k}=\delta_{H C I S-N P S k}(n, \Delta t) \\
=\frac{K_{H C I S-N P S k}(n \Delta t)-K_{H C I S-N P S k}((n-1) \Delta t)}{\Delta t}
\end{gathered}
$$

$$
\begin{aligned}
& k_{H C I S-N P S k}=\frac{K_{H C I S-N P S k}}{d t}=\frac{C_{R} U(t-\alpha) \exp ^{-\epsilon \alpha}}{\left(1+\in T_{1}\right)}\left[B_{5}\right] \\
& +\frac{C_{L} U(t-\alpha) \exp ^{-\epsilon \alpha}}{1+\in T}\left[B_{5}\right]-\psi C_{L} U(t-\alpha)\left[B_{6}+B_{7}\right] \\
& +\psi C_{L}\left[B_{6}-B_{7}\right]+\frac{\psi C_{L} T_{1}}{\left(1+\in T_{1}\right)}\left[B_{5}\right]+\frac{\psi C_{L} T_{2}}{\left(1+\in T_{2}\right)}\left[B_{8}\right]
\end{aligned}
$$

...where:

$$
\begin{aligned}
& B_{5}=\left[\frac{\exp ^{-\left[\frac{\left.1+T_{2}\right]}{T_{2}}\right](t-\alpha)}}{T_{2}}+\frac{1+\in T_{1} \exp ^{-\left[\frac{\left.1+T_{1}\right]}{T_{1}}\right](1-\alpha)}-T_{1}\left(1+\in T_{2}\right) \exp ^{-\left[\frac{\left[1 \in T_{2}\right.}{T_{2}}\right](1-\alpha)}}{T_{2}\left(T_{1}-T_{2}\right)}\right], \\
& B_{6}=\left[-\in \exp ^{-\epsilon \epsilon}+\frac{1+\in T_{2} \exp ^{-\epsilon \alpha} \exp ^{\left.-\frac{\left[1+\epsilon T_{2}\right]}{T_{2}}\right](1-\alpha)}}{T_{2}}\right], \\
& B_{8}=\left[\frac{1+\in T_{2} \exp ^{-\left[\frac{\left.1+T_{2}\right]}{T_{2}}\right](t-\alpha)}}{T_{2}}\right], \\
& B_{7}=\left[-\frac{\exp ^{-\epsilon \propto}\left[1+\in T_{1} \exp ^{-\left[\frac{[1 \in \epsilon]}{T_{1}}\right](1-\alpha)}+T_{1}\left(1+\in T_{2}\right) \exp ^{-\left[\frac{\left.1+\epsilon T_{2}\right]}{T_{2}}\right](1-\alpha)}\right]}{T_{2}\left(T_{1}-T_{2}\right)}\right],
\end{aligned}
$$

Eq. (17) describes the temporal variation in concentration that corresponds to the unit impulse input at the boundaries valid for $t \geq \alpha$.

Through method of convolution applied by discrete kernel method, the fate of the pollutants at downstream locations of the river channel in later hybrid units is simulated.

$$
D(\mathrm{~m}, t)=\int_{0}^{t} c[(m-1), \tau] \psi(t-\tau) d \tau
$$

...using numerical integrals Eq. (18) reduces to Eq. (19):

$$
\begin{gathered}
C(\mathrm{~m} \Delta x, n \Delta t) \\
=\sum_{\gamma=1}^{n} C[(m-1) \Delta x, \mathrm{n} \Delta t] \delta_{H C I S-N P S k}[(n-\gamma+1), \Delta t]
\end{gathered}
$$

Eq. (19) produces the response at the $m$ th hybrid unit, when $m \geq 2$ for any number of hybrid units along the river reach.

\section{Results and Discussion}

Testing the Proposed Model

In testing the proposed model, an artificial situation is considered to demonstrate its potential for simulating non-conservative pollutants and NPS inflows. A conceptualised $3 \mathrm{~km}$ river is assumed to have a cross-sectional area of $20 \mathrm{~m}^{2}$, with a flow rate $\mathrm{Q}$ given as $400 \mathrm{~m}^{3} / \mathrm{min}$. The dispersion coefficient $\mathrm{D}_{\mathrm{L}}$ is 


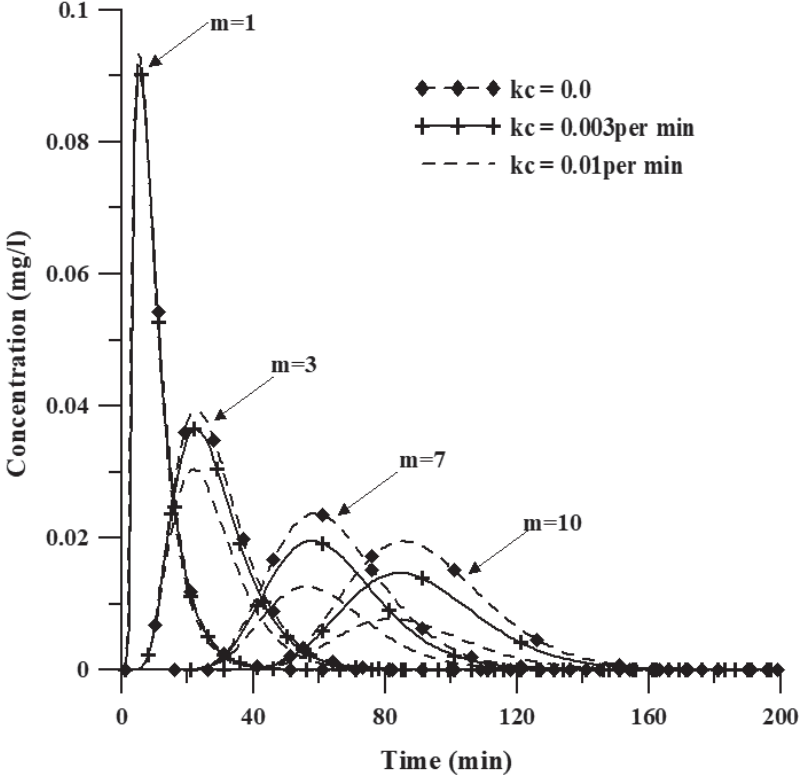

Fig. 2. Concentration of pollutants in response to unit impulses of HCIS-NPSk model with varied decay constants $k_{a}=0,0.01$ and 0.003 per min, at the $1^{\text {st }}, 3^{\text {rd }}, 7^{\text {th }}$ and $10^{\text {th }}$ hybrid units, which represents different points of $\mathrm{x}$ at 200,600, 1400 and $2000 \mathrm{~m}$ respectively from source.

$1000 \mathrm{~m}^{2} / \mathrm{min}$ while the flow velocity $u$ is $20 \mathrm{~m} / \mathrm{min}$. the values for lateral inflow $\mathrm{q}_{\mathrm{L}}$ and pollutant concentration from lateral inflow $C_{L}$ are set at $0.016 \mathrm{~m}^{3} / \mathrm{min} / \mathrm{m}$ and $0.08 \mathrm{mg} / \mathrm{l} . \Delta \mathrm{x}$ the size of the hybrid unit is $200 \mathrm{~m}$, while the decay rate coefficient $k_{a}$ is varied from 0 , 0.01 and 0.003 per min. The resident time parameters are estimated with Eqs (3)-(5). The impulse responses generated for the first, third, seventh and tenth hybrid units with respect to time at different sections of the river from the near field were simulated using Eq. (17) and (19) and is presented as Fig. 2, which shows that all the graphs exhibit a bell-shaped distribution curve with elongated tails. As the pollutant plume moves downstream, attenuation of the C-t curve occurs and peak concentrations and time-to-peak is reduced further downstream with the increase in hybrid units. The peak concentration reduces while the falling limb is elongated with an increase in hybrid units. The profiles of the impulse response showed that with the higher decay rate of 0.01 per min, there was a slight reduction in peak concentration within the first hybrid. However, a significant reduction in peak concentrations was obvious as the plume arrived $600 \mathrm{~m}$ downstream and further downstream. Within the first hybrid unit, however, the lower decay rate of 0.003 per min was not that obvious as it matched the profile without any decay. However, it showed a marked decrease in concentration levels in later hybrids. In general, it is obvious that the C-t profiles with decay show rapid attenuation as the pollutant moves farther downstream when compared to that without decay. Consequently, the higher the decay constant, the lower the pollutant concentration with respect to time. Fig. 3 shows peak

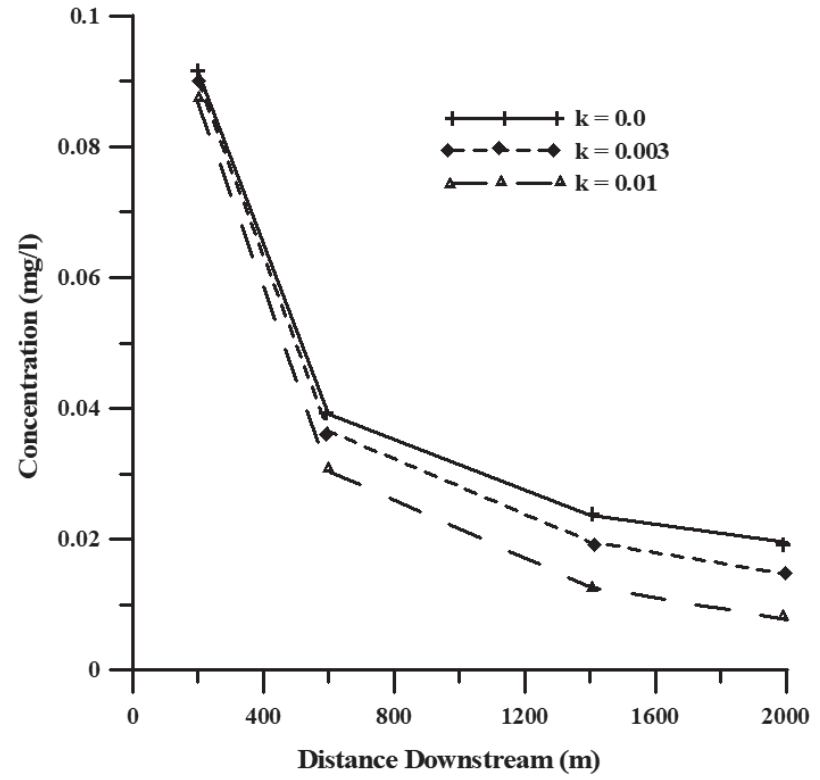

Fig. 3. Peak concentration of pollutants along the river reach at $x=200,600,1400$ sand $2000 \mathrm{~m}$ for varied kinetic constants.

concentration of solute at downstream locations of $200 \mathrm{~m}, 600 \mathrm{~m}, 1400 \mathrm{~m}$ and $2000 \mathrm{~m}$.

The model is further tested for varying NPS inputs and decay constants to demonstrate its response to instream conditions. First simulations are performed without inclusion of NPS inflows and decay of pollutants. Next, NPS input of $1.8 \mathrm{mg}^{-1}$ of $\mathrm{C}_{\mathrm{L}}$ and $\mathrm{q}_{\mathrm{L}}$ of $0.16 \mathrm{~m}^{3} \mathrm{~min}^{-1} \mathrm{~m}^{-1}$ with a decay constant ka of 0.01 is introduced, while subsequent simulations alternate NPS input and decay reaction. The response of the model to these variations is presented in Fig. 3. The response

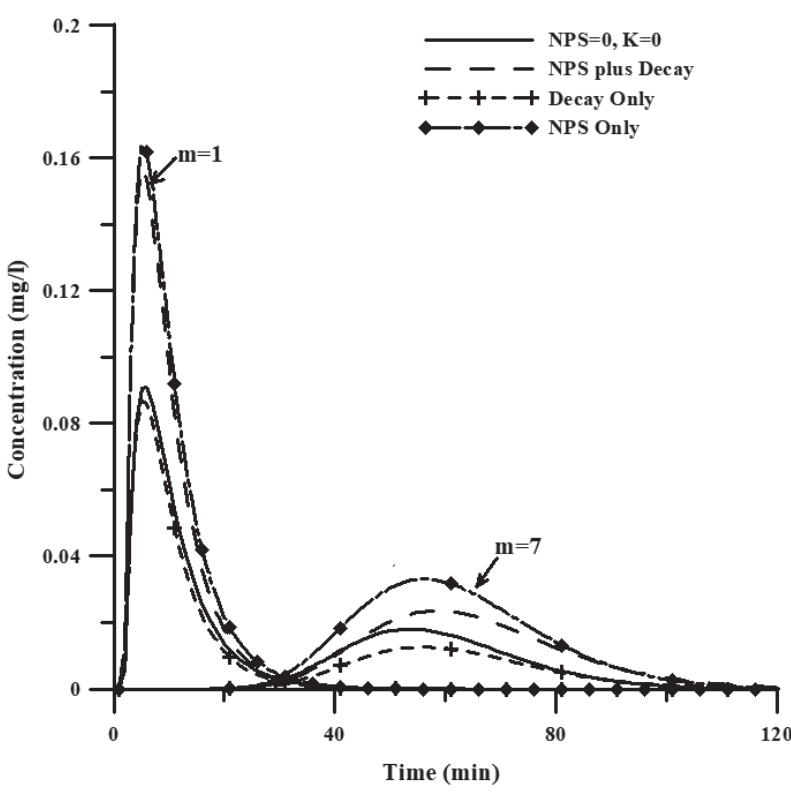

Fig. 4. Concentration of pollutants in response to unit impulses of HCIS-NPSk model under varying conditions of NPS inputs of $\mathrm{C}_{\mathrm{L}}=0, \mathrm{q}_{\mathrm{L}}=0$, and $\mathrm{C}_{\mathrm{L}}=1.8, \mathrm{q}_{\mathrm{L}}=0.16, k_{a}=0,0.01$ per min, for the $1^{\text {st }}$ and $7^{\text {th }}$ hybrid units. 
of the model shown in Fig. 4 is consistent with the expected response of model for the varying conditions.

\section{Testing and Validating the HCIS-NPSk with ADE-NPSk Model}

In order to assess the adequacy of the proposed HCIS-NPS $k$ model, the model is compared with the advection dispersion equation (ADE) model. The explicit finite difference method is used to numerically solve Eq. (20), which is the classical ADE inclusive of decay and non-point source components otherwise denoted as ADE-NPS $k$. The solution is compared with the results obtained from the HCIS-NPS $k$ model when all boundary conditions are maintained and satisfied.

$$
\begin{gathered}
\frac{\partial C(x, t)}{\partial t}=-u \frac{\partial C(x, t)}{\partial x}+D_{L} \frac{\partial^{2} C(x, t)}{\partial x} \\
+\frac{q_{L}}{A}\left(C_{L}-C(x, t)\right)-k_{a} C(x, t)
\end{gathered}
$$

...where $C(x, t)\left(\mathrm{mgl}^{-1}\right)$ is the pollutant concentration in the water body, $u\left(\mathrm{~ms}^{-1}\right)$ is flow velocity of the water body, $t(\mathrm{~s})$ is time interval of solute displacement, $x(\mathrm{~m})$ is distance from source, $D_{L}\left(\mathrm{~m}^{2} \mathrm{~s}^{-1}\right)$ is the longitudinal dispersion coefficient, $q_{L}\left(\mathrm{~m}^{3} \mathrm{~s}^{-1} \mathrm{~m}^{-1}\right)$ is lateral inflow, $A\left(\mathrm{~m}^{2}\right)$ is the cross-sectional area of water channel, $C_{L}\left(\mathrm{mgl}^{-1}\right)$ is pollutant concentration in lateral inflow, and $k_{\mathrm{a}}\left(\mathrm{s}^{-1}\right)$ is the first-order decay constant. Eq. (20) is solved with the forward difference in time, backward upwind for advection, and central difference in space for dispersion equations (21), (22) and (23):

$$
\begin{gathered}
\frac{\partial C(x, t)}{\partial t}=\frac{C(x, t+\Delta t)-C(x, t)}{\Delta t} \\
\frac{\partial C(x, t)}{\partial x}=\frac{C(x+\Delta x, t)-C(x-\Delta x, t)}{2 \Delta x} \\
\frac{\partial^{2} C(x, t)}{\partial x^{2}}=\frac{C(x+\Delta x, t)-2 C(x, t)+C(x-\Delta x, t)}{\Delta x^{2}}
\end{gathered}
$$

The solution of Eq. (20) gives the step response of the ADE-NPSk given as Eq. (24):

$$
\begin{gathered}
C(x, t+\Delta t)=\left(C(x, t)\left[1-\frac{2 D_{L} \Delta t}{\Delta x^{2}}-\frac{q_{L}}{A} \Delta t-k_{a} \Delta t\right]\right) \\
-\left(C(x+\Delta x, t)\left[\frac{u \Delta t}{2 \Delta x}-\frac{D_{L} \Delta t}{\Delta x^{2}}\right]\right) \\
+\left(C(x-\Delta x, t)\left[\frac{u \Delta t}{2 \Delta x}+\frac{D_{L} \Delta t}{\Delta x^{2}}\right]\right)+\left(C_{L}\left[\frac{q_{L}}{A} \Delta t\right]\right)
\end{gathered}
$$

Eq. (24) is numerically differentiated with respect to time in order to obtain the impulse response of the ADE-NPSk. As previously stated, synthetic data is used for the simulation of both models. While ensuring that in selecting a uniform space step and time step for the ADE-NPS $k$ model, the Courant number did not exceed 1 in order to reduce the oscillations and ensure numerical stability. The response of both models at downstream locations of $200 \mathrm{~m}, 600 \mathrm{~m}, 1400 \mathrm{~m}$ and $2000 \mathrm{~m}$ for a $3 \mathrm{~km}$ river reach (represented as $1^{\text {st }}$, $3^{\text {rd }}, 7^{\text {th }}$ and $10^{\text {th }}$ hybrid units) is presented in Fig. 5. Both models were simulated in response to first-order decay of 0.01 per min at the same distance downstream. For each simulation run, peak concentration and time-to-peak were compared. It is noted that both models present a steep rising limb and right-skewness in the first hybrid unit, which is subsequently reduced to a normal distribution with an increase in hybrid units. However, the HCIS-NPS $k$ model had elongated tails when compared to the ADE model as the pollutant travelled downstream. Also, with an increase in distance from the location of pollutant release, both models produce $\mathrm{C}$-t profiles with time-to-peak occurring at approximately the same time. Differences, however, in peak concentrations of the $\mathrm{C}$-t profiles for ADE-NPS $k$ and HCIS-NPS $k$ models are observed as the pollutant travelled downstream as seen in Fig. 5. Peak concentrations attenuate more rapidly with the HCIS-NPS $k$ model than the ADE-NPS $k$. Hence the response of the HCIS-NPS $k$ model is consistent with investigations of solute transport

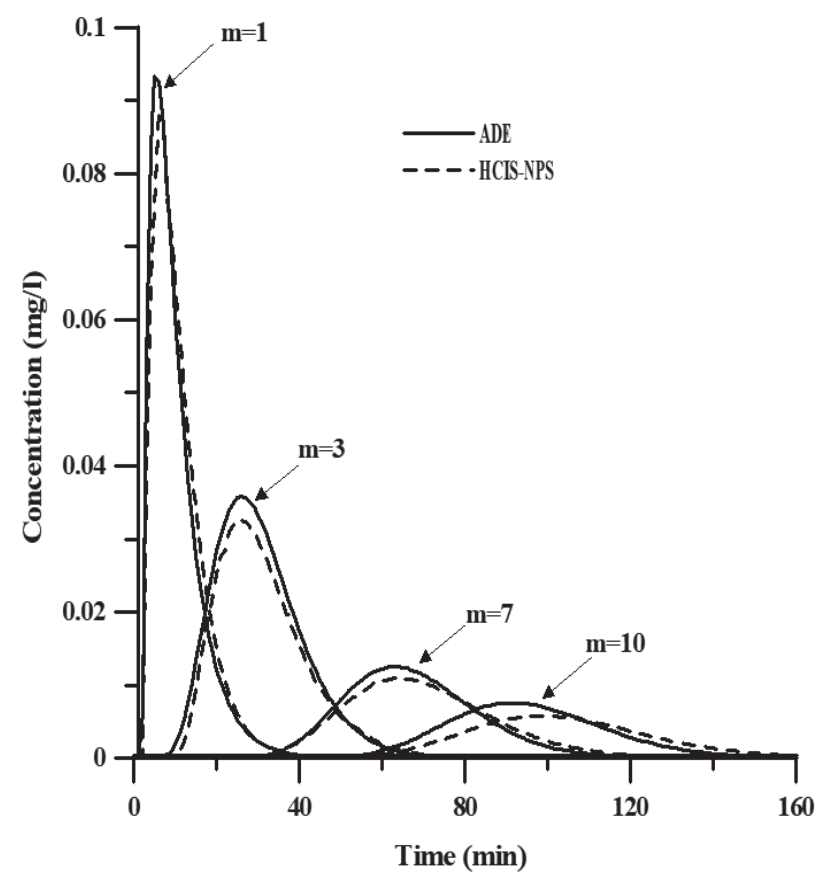

Fig. 5. Comparison of pollutants concentration unit impulse response of ADE-NPS $k$ model and HCIS-NPS $k$ model with decay rate coefficient $k_{a}=0.01$ per min, at the $1^{\text {st }}, 3^{\text {rd }}, 7^{\text {th }}$ and $10^{\text {th }}$ hybrid units, which represents different points of $x$ at 200,600, 1400 and $2000 \mathrm{~m}$ respectively from source. 
in rivers. At $95 \%$ confidence level, the performance of HCIS-NPS $k$ to the ADE-NPS $k$ was tested. The coefficient of determination $\left(\mathrm{R}^{2}\right)$ and the standard error (SE) were within the range of 0.895 to 0.996 and $2.52 \mathrm{E}-3$ to $4.24 \mathrm{E}-4$ respectively. This result is indicative of a good correlation between both models. Both models respond to the effect of the first-order kinetic reaction taking place within the water channel and down-stream.

\section{Conclusions}

A clear majority of non-conservative/reactive pollutants have been identified as being sourced from non-point sources - especially from agricultural settlements and urban areas situated within close proximities to open water channels. Considering this, a hybrid cells in series, non-point source model with an added component for simulation of first-order reaction kinetics (HCIS-NPS $k$ ) is proposed. The proposed model is tested using artificial data because field tracer tests for simulation of non-conservative pollutants are performed with the use of conservative pollutants due to the ethical requirements for use of non-conservative pollutants. Therefore, mathematical models simulate non-conservative pollution/decay with the use of synthetic data.

Most NPS models are basically watershed-based models that require large data sets with computational difficulties and are based on the Fickian ADE model. Thus, the simulated results of the HCIS-NPSk model were compared to the numerical solution of the advection dispersion equation model inclusive of non-point source and first-order reaction kinetics components (ADE-NPSk). The response of the model with differing decay rate coefficient and under varying pollutant loading conditions demonstrates its ability to adequately simulate decay in a natural river. Also, the response of the HCIS-NPS $k$ matches that of the ADENPS $k$, but with a longer tail that adequately interprets experimental results as expressed in literature. The advantage of this model over other models lies in its simplicity and ease in computation, with low data requirement. The model is also flexible and has the capacity for the addition of other components. The simplicity of the HCIS model makes it a viable tool for simulation of decay-prone contaminant transport from non-point sources. The effect of transient storage or hyporheic zones which is considered responsible for the long arrival and trailing tails observed in field tracer tests is, however, not considered in this model. Further attempts to incorporate this phenomenon into the model will be implemented. It is also imperative that the model is validated through actual field data after storm events, since most parameters are assumed. However, the concept is adequate for use as a guide when modelling such events.

\section{Acknowledgements}

The authors express their gratitude for the support provided by the Water Research Commission in South Africa for this research through project K5/2328.

\section{Conflict of Interest}

The authors declare no conflict of interest.

\section{References}

1. LÓPEZ M.E.P., SANCHEZ-MARTINEZ M.G., DE LA ROSA M.G.V., LEON M.T. Eutrophication Levels through San Pedro-Mezquital River Basin. Journal of Environmental Protection, 4 (11), 45, 2013.

2. GAO X.P., LI G.N., LI G.R., ZHANG C. Modeling the effects of point and non-point source pollution on a diversion channel from Yellow River to an artificial lake in China. Water Science \& Technology, 71, 1806, 2015.

3. WEN Y., SCHOUPS G., VAN DE GIESEN N. Organic pollution of rivers: Combined threats of urbanization, livestock farming and global climate change. Scientific reports, 7, 43289, 2017.

4. KUMARASAMY M., GHOSH N.C., MISHRA G.C. KANSAL M.L. Hybrid model development for the decaying pollutant transport in streams. International Journal of Environment and Waste Management, 12 (2), 130, 2013.

5. NYENJE P.M., FOPPEN J.W., UHLENBROOK S., KULABAKO R., MUWANGA A. Eutrophication and nutrient release in urban areas of sub-Saharan Africa a review. Science of the Total Environment, 408 (3), 447, 2010.

6. VAROL M., ŞEN B. Assessment of nutrient and heavy metal contamination in surface water and sediments of the upper Tigris River, Turkey. Catena, 92, 1, 2012.

7. KIEDRZYŃSKA E., KIEDRZYŃSKI M., URBANIAK M., MAGNUSZEWSKI A., SKŁODOWSKI M., WYRWICKA A., ZALEWSKI M. Point sources of nutrient pollution in the lowland river catchment in the context of the Baltic Sea eutrophication, Ecological engineering, 70, 337, 2014.

8. MCDOWELL R.W., COX N., SNELDER T.H. Assessing the Yield and Load of Contaminants with Stream Order: Would Policy Requiring Livestock to Be Fenced Out of High-Order Streams Decrease Catchment Contaminant Loads? Journal of environmental quality, 46 (5), 1038, 2017.

9. GAVRILESCU M., DEMNEROVÁ K., AAMAND J., AGATHOS S., FAVA F. Emerging pollutants in the environment: present and future challenges in biomonitoring, ecological risks and bioremediation. New biotechnology, 32 (1), 147, 2015.

10. YUCEER M., COSKUN M.A. Modeling water quality in rivers: a case study of Beylerderesi river in Turkey. Applied Ecology and Environmental Research, 14 (1), 383, 2016.

11. JIAKE L., HUAIEN L.I., BING S.H.E.N., YAJIAO L.I. Effect of non-point source pollution on water quality of the Weihe River. International Journal of Sediment Research, 26 (1), 50, 2011. 
12. MUELLER-WARRANT G.W., GRIFFITH S.M., WHITTAKER G.W., BANOWETZ G.M., PFENDER W.F., GARCIA T.S., GIANNICO G.R. Impact of land use patterns and agricultural practices on water quality in the Calapooia River Basin of western Oregon. Journal of Soil and Water Conservation, 67 (3), 183, 2012.

13. POUDEL D.D., LEE T., SRINIVASAN R., ABBASPOUR K., JEONG C.Y. Assessment of seasonal and spatial variation of surface water quality, identification of factors associated with water quality variability, and the modeling of critical nonpoint source pollution areas in an agricultural watershed. Journal of Soil and Water Conservation, 68 (3), $155,2013$.

14. ABON C.C., NGUYEN T.C., SHAMS S., PHAN D.V., HUONG D.T.T. River Pollution. National University of Singapore, 2009.

15. LOUCKS D.P., VAN BEEK E. Water Quality Modeling and Prediction. Springer, Cham, 417, 2017 [In Water Resource Systems Planning and Management].

16. VOß A., ALCAMO J., BÄRLUND I., VOß F., KYNAST E., WILLIAMS, R., MALVE O. Continental scale modelling of in-stream river water quality: a report on methodology, test runs, and scenario application. Hydrological Processes, 26 (16), 2370, 2012.

17. CORRIVEAU J., VAN BOCHOVE E., SAVARD M.M., CLUIS D., PARADIS D. Occurrence of high instream nitrite levels in a temperate region agricultural watershed. Water, air, and soil pollution, 206 (1-4), 335, 2010.

18. OLIVEIRA B., BOLA J., QUINTEIRO P., NADAIS H., ARROJA L. Application of Qual2Kw model as a tool for water quality management: Cértima River as a case study. Environmental monitoring and assessment, 184 (10), 6197, 2012.
19. NURUZZAMAN M., AL-MAMUN A., SALLEH M.N.B. Experimenting biochemical oxygen demand decay rates of Malaysian river water in a laboratory flume. Environmental Engineering Research, 23 (1), 99, 2017.

20. BEAR J. Dynamics of fluids in porous media-American Elsevier pub. Comp., Inc. New York, pp. 764, 1972.

21. FISCHER H.B. Dispersion predictions in natural streams. J. Sanit. Eng. Div., ASCE, 94, 927, 1968.

22. BENEDINI M., TSAKIRIS G. Water quality modelling for rivers and streams. Springer Science \& Business Media, 2013.

23. GHOSH N.C. Study of solute transport in a river. $\mathrm{PhD}$ Thesis, Dept. of Civil Eng., IIT, Roorkee, India, 2001.

24. FISCHER H.B., LIST E., KOH R., IMBERGER J., BROOKS, N. Mixing in Inland and Coastal Waters Academic Press. New York. 1979.

25. KI S.J., HWANG J.H., KANG J.H., KIM J.H. An analytical model for non-conservative pollutants mixing in the surf zone. Water Science and Technology, 59 (11), 2117, 2009.

26. KAHIL M.A. Application of First Order Kinetics for Modeling Chlorine Decay in Water Networks. International Journal of Scientific \& Engineering Research, 7 (11), 331, 2016.

27. GHOSH N.C., MISHRA G.C., OJHA C.S.P. Hybrid-cellsin-series Model for Solute Transport in a River. Journal of Environmental Engineering, 130 (10), 1198, 2004.

28. GHOSH N.C., MISHRA G.C., KUMARASAMY M. Hybrid-cells-in-series model for solute transport in streams and relation of its parameters with bulk flow characteristics. Journal of Hydraulic Engineering, 134 (4), 497, 2008. 
